Rabaska

Revue d'ethnologie de l'Amérique française

\title{
Musée de la mémoire vivante (Saint-Jean-Port-Joli)
}

\section{Judith Douville}

Volume 17, 2019

URI : https://id.erudit.org/iderudit/1066051ar

DOI : https://doi.org/10.7202/1066051ar

Aller au sommaire du numéro

Éditeur(s)

Société québécoise d'ethnologie

ISSN

1703-7433 (imprimé)

1916-7350 (numérique)

Découvrir la revue

Citer ce document

Douville, J. (2019). Musée de la mémoire vivante (Saint-Jean-Port-Joli). Rabaska, 17, 389-391. https://doi.org/10.7202/1066051ar d'utilisation que vous pouvez consulter en ligne.

https://apropos.erudit.org/fr/usagers/politique-dutilisation/ 


\section{QUÉBEC}

Musée de la mémoire vivante

710, avenue de Gaspé Ouest

Saint-Jean-Port-Joli (Québec)

G0R 3G0
Téléphone : (418) 358-0518

Courriel : information@memoirevivante.org

Toile : www.memoirevivante.org

Le Musée de la mémoire vivante capte, conserve, étudie et met en valeur les savoirs, savoir-faire et mode de vie de quiconque désire les lui confier, et cela, dans un but de sauvegarde et de diffusion.

\section{Une année festive}

Le Musée de la mémoire vivante a souligné son dixième anniversaire avec la communauté et les Amis du Musée. Deux événements d'envergure ont marqué le début de la saison touristique. La plantation du mai, une tradition qui a été reproduite en collaboration avec les Rendez-vous Ononthio et les Arquebusiers de Kébec. Un événement propre au site sur lequel est situé le Musée, soit celui du manoir des Aubert de Gaspé. Une journée porte ouverte et au cours de l'année, une succession d'activités gratuites ont été présentées à des publics de tous âges. Des conférences directement liées aux expositions en salle ont été prononcées par des invités ou des membres du personnel. La teinture à base de champignons sauvages, la pêche à l'anguille, les jouets de bois, la transmission orale et les traditions alimentaires ne sont que quelques-uns des sujets abordés.

\section{Dossiers déposés au ministère de la Culture et des communications}

Lors de la fondation du Musée de la mémoire vivante, en 2008, un moratoire sur la reconnaissance des institutions muséales était en vigueur. En 2018, le ministère de la Culture et des communications au nom du gouvernement du Québec a demandé aux musées qu'il a reconnus ou non par le passé de soumettre une demande d'agrément. Au moment de rédiger ce rapport, le Musée a reçu le statut d'institution muséale agréée. Toute l'équipe s'engage à maintenir et bonifier ses actions qui ont valu au Musée ce sceau d'excellence en fonction de sa performance.

À la suite des recherches effectuées pour la préparation de l'exposition $L a$ Pêche à l'anguille sur la Côte-du-Sud, la MrC de Kamouraska a mandaté le Musée pour que soit déposée une demande de désignation de la pêche à l'anguille en tant qu'élément du patrimoine immatériel du Québec. La Mrc et le Musée sont dans l'attente d'une décision.

\section{La collection}

La collection du Musée est majoritairement immatérielle étant constituée de récits et de témoignages sur supports numériques. Cette année, plus de 150 captations ont été réalisées sur diverses thématiques. Certaines sont typiques d'une époque et souvent méconnues des jeunes générations. Citons, par exemple, les boîtes à chansons, les tavernes et les écoles de rang. 
De nombreux témoins ou informateurs viennent au Musée pour enregistrer leurs savoirs et savoir-faire. Avec le programme Le Musée de la mémoire vivante sur la route, plusieurs captations ont été réalisées hors les murs. Les partenariats conclus avec des organismes de différentes régions du Québec se sont poursuivis et bonifient la collection.

Le Musée possède une petite collection matérielle. Les artéfacts qui la composent sont, entre autres, liés aux Aubert de Gaspé. Cette année, la famille de Gaspé Beaubien a fait don au Musée d'une copie photographique reliée plein cuir du manuscrit «Les Anciens Canadiens » de Philippe Aubert de Gaspé. Cet artéfact est présenté au public dans l'exposition Philippe Aubert de Gaspé, l'héritage remarquable d'un ancien Canadien.

\section{Les expositions}

Trois expositions ont été inaugurées en 2018. À l'été, Hockey, réalisée par le Musée canadien de l'histoire, invitait à prendre la mesure du phénomène de société entourant ce sport. Le Musée y a intégré des témoignages sur le sujet. L'exposition virtuelle, $L a$ Pêche à l'anguille sur la Côte-du-Sud, hébergée par le Musée virtuel du Canada a été mise sur la toile en août. À l'automne, l'exposition Excusez-la ! a pris l'affiche. Elle traite de la chanson traditionnelle francophone au moyen de témoignages provenant du Québec, de l'Ontario et de l'Alberta.

Le Musée est présent dans plusieurs expositions réalisées par d'autres institutions muséales. Le prêt de ses témoignages ou de nouvelles captations sur des sujets précis lui sont souvent demandés. Ce fut le cas, notamment, avec le Musée Laurier, le Musée Pop et le Musée québécois de l'agriculture et de l'alimentation. Des organisations ont fait aussi de telles demandes. Il s'agit du Centre franco-ontarien de folklore (Sudbury), de la Ville de Québec et celle de Montmagny.

\section{Accueils étudiants}

Le Musée a contribué à la formation de la relève en muséologie par l'accueil de stagiaires de l'Université de Sherbrooke et de l'Université Laval. Il a pris part à l'enquête estivale dirigée par la Société des musées du Québec sur la provenance et la satisfaction des visiteurs. Les résultats obtenus montrent un haut taux de satisfaction.

Des étudiants de l'Université de Montréal et de l'Université d'Ottawa sont également venus rencontrer les dirigeants du Musée dans le cadre de recherches sur la mise en musée de l'oralité.

\section{Le site extérieur}

Le Musée est situé dans un parc offrant à ses visiteurs l'expérience d'une promenade en forêt ou sur la rive du fleuve. Deux bâtiments datant des XVIII et XIX ${ }^{\mathrm{e}}$ siècles marquent la vie passée sur cet emplacement. L'an dernier a pris forme un projet de construction d'une tour pour avoir accès au belvédère. Appelée Tour de l'innovation, elle est érigée pour rendre hommage aux innovateurs et innovatrices qui ont contribué au développement économique, social et culturel de la région. Depuis la tour, des gens pourront écouter des extraits de témoignages en utilisant leur téléphone mobile. 
Le Musée est très présent dans la communauté. Il rejoint les plus jeunes par son programme scolaire virtuel et est partenaire d'événements tels la Biennale de sculpture ou la Fête des chants de marins. Il est devenu une destination culturelle pour la population régionale et les touristes désireux de vivre une expérience muséale différente.

Judith DouviLle

\section{Le Centre de conservation du Québec}

Ministère de la Culture et des communications 1825 , rue Semple

Québec (Québec)

G1N 4B7

Téléphone : (418) 643-7001

Courriel : ccq@mcc.gouv.qc.ca

Toile : www.ccq.gouv.qc.ca

Le $1^{\text {er }}$ avril 2019 marquait le $40^{\text {e }}$ anniversaire de la création du Centre de conservation du Québec. C'est en effet en 1979 que le ministère des Affaires culturelles de l'époque rassemblait un premier groupe de trois restaurateurs de biens culturels et leur adjoignait un directeur, une secrétaire et un photographe pour entamer un périple qui serait des plus bénéfiques pour la conservation du patrimoine québécois. Aujourd'hui, l'équipe du CCQ regroupe plus d'une quarantaine de personnes, dont une trentaine de restauratrices et restaurateurs professionnels.

\section{Réalisations du personnel du CCQ}

Au cours de la dernière année, les réalisations du personnel du Centre ont été nombreuses :

- Production de plus de 25400 heures de services de restauration, d'expertise ou de formation, dont plus de 15200 ont été financées par le ministère de la Culture et des communications, et près de 10200 ont été facturés aux clientèles.

- Participation au sauvetage du rempart palissadé de Beaucours, mis au jour à l'automne 2018 lors de travaux de construction dans le Vieux-Québec. L'expertise des restaurateurs du CCQ a été essentielle pour que l'extraction des vestiges soit faite dans les règles de l'art afin de pouvoir les mettre rapidement à l'abri du gel et entamer le traitement qui permettra leur conservation et leur éventuelle mise en valeur. - Préparation d'un Plan d'intervention en cas de sinistre par deux restauratrices du CCQ, en collaboration avec des professionnels du ministère de la Culture et des communications. Il sera diffusé aux clientèles cibles au cours de l'exercice financier 2019-2020 afin de les aider à mieux se préparer s'ils devaient subir un sinistre et à poser les bons gestes pour protéger leurs biens patrimoniaux lorsque ce risque se matérialise.

- Finalisation de la rédaction d'une synthèse des travaux de restauration des artéfacts extraits de l'épave du Elizabeth \& Mary. Elle présentera plus de 25 ans de travaux ayant permis de conserver et de mettre en valeur des centaines d'objets qui nous aident à mieux comprendre le contexte historique de l'attaque de Phipps sur Québec en 1690. Cette synthèse devrait être publiée au cours de l'année 2020. 